\title{
MICROWAVE CONDUCTIVITIES OF POLYMER FILMS DOPED WITH BEDT-TTF POLYIODIDES
}

\author{
D. Staerk, H.W. Helberg
}

Third Physical Institute, University of Göttingen, 37073 Göttingen, Germany

\section{J. ULAŃSKI}

Polymer Institute, Technical University of Łódż, 90-924 Łódź, Poland

AND J.K. JESZKA

Center of Molecular and Macromolecular Studies, 90-363 Eódź, Poland

\begin{abstract}
Conducting reticulate doped polymeric films containing BEDT-TTF iodide crystalline networks have been annealed in order to transform the crystallites into crystal phases with metallic conductivity. The microwave conductivity of these films was measured before and after annealing. The temperature dependence of the conductivity changes dramatically with optimal annealing temperatures and times. This change in the behavior corresponds to the transformation of the $\alpha$-phase into the superconducting $\alpha_{t}$-phase observed in (BEDT-TTF) ${ }_{2} \mathrm{I}_{3}$ single crystals.
\end{abstract}

PACS numbers: 72.80.Le, 72.60.+g, 78.70.Gq

\section{Introduction}

Conducting polymeric materials have been prepared by reticulate doping [1]. A small amount $(\approx 2 \mathrm{wt} . \%)$ of an organic conducting salt or complex forms a continuous network of crystallites in the polymer matrix during the casting process. In addition, a special casting technique yields conducting polymers with high anisotropy of the conductivity [2,3].

Recently conducting reticulate doped polymer films have been prepared containing a low amount of organic salt crystallites, which are transformed into superconducting phases by annealing [4]. Such superconducting polymer films are very interesting due to their potential applications. In the present paper the microwa ve conductivity in dependence on annealing temperature and annealing time is discussed. Parallel to these investigations absorption spectra of these films were measured in the VIS and NIR range [5]. 


\section{Experimental}

During casting an amount of $2 \mathrm{wt} . \%$ of BEDT-TTF is molecularly dispersed in polycarbonate films about $20 \mu \mathrm{m}$ in thickness [4]. Then one surface of the film is exposed to solvent/iodine vapour. In the swollen film the BEDT-TTF molecules become movable. In a small layer below the film surface reaction between BEDT-TTF

and iodine takes place forming a thin conducting layer (thickness $\approx 5 \mu \mathrm{m}$ ) containing tiny microcrystals of BEDT-TTF polyiodide salts. Annealing at $100^{\circ}, 110^{\circ}$, $120^{\circ}$, and $130^{\circ} \mathrm{C}$ with several annealing times are applied to these films in order to transform the BEDT-TTF polyiodide crystallites into other crystal phases with metallic conductivity or even superconductivity (e.g. $\alpha_{t}$-phase, $\beta^{*}$-phase) $[4,6]$. In single crystals the $\alpha$-phase could be transformed into the $\alpha_{t}$-phase due to the thermal treatment

$$
\alpha-(\mathrm{ET})_{2} \mathrm{I}_{3} \stackrel{T \geq 70^{\circ} \mathrm{C}}{\longrightarrow} \alpha_{t}-(\mathrm{ET})_{2} \mathrm{I}_{3} .
$$

The well-known phase transition at $135 \mathrm{~K}$ of the $\alpha$-phase then disappears and the new phase becomes superconducting at $6-8 \mathrm{~K}[7,8]$.

The microwave measurements were carried out in a cylindrical cavity, working in the $\mathrm{TM}_{010}$ mode at $10.2 \mathrm{GHz}$ applying the perturbation technique $[9,10]$.

\section{Results and discussion}

Without annealing the microwave conductivities of these films at room temperature are about $4-8 \times 10^{-1}(\Omega \mathrm{cm})^{-1}$. Betweeen room temperature and $150 \mathrm{~K}$ there is a weak and below $150 \mathrm{~K}$ a strong decrease in the conductivity (three orders of magnitude) to $1 \times 10^{-3}(\Omega \mathrm{cm})^{-1}$ at $4 \mathrm{~K}$ (see Fig. 1a). The curves are similar to those measured on the pressed polycrystalline samples of $\alpha$-(BEDT-TTF $)_{2} \mathrm{I}_{3}[10]$. But in contrast to the sharp decrease at $135 \mathrm{~K}$ in single crystals [11], the transition in our case and in the pressed samples is broadened and shifted to higher temperatures, obviously because of the fine grain crystal structure. This corresponds though in a weaker form - to the known sharp phase transition of single crystalline $\alpha$-(BEDT-TTF $)_{2} \mathrm{I}_{3}$ at $135 \mathrm{~K}$. Thus we suggest that the conductivity in unannealed films is governed by the $\alpha$-phase. Activation energies in this transition region (150-4 K) are $10-73 \mathrm{meV}$.

Similar to annealed single crystals the conductivity of these polymeric films changes dramatically due to the thermal treatment. In order to investigate the transformation from the $\alpha$-phase into the $\alpha_{t}$-phase in this case, stepwise annealing was applied to the same sample. After every annealing procedure the microwave conductivity was measured.

Figure 1a summarizes results for stepwise annealing. The room temperature conductivity decreases with longer total annealing times, while the low temperature conductivity increases, so that the behavior of these films become metallic over the whole temperature range. All curves are intersecting in an isoconductive point at ca. $100 \mathrm{~K}$. Therefore (similar to [10]) the assumption could be made that the 0 min. curve corresponds to the $\alpha$-phase and the extremal curve (24 min.) to the $\alpha_{t}$-phase, respectively. Then all curves in between are due to a mixture of the two phases. The volume fraction of this two-component system in dependence on 

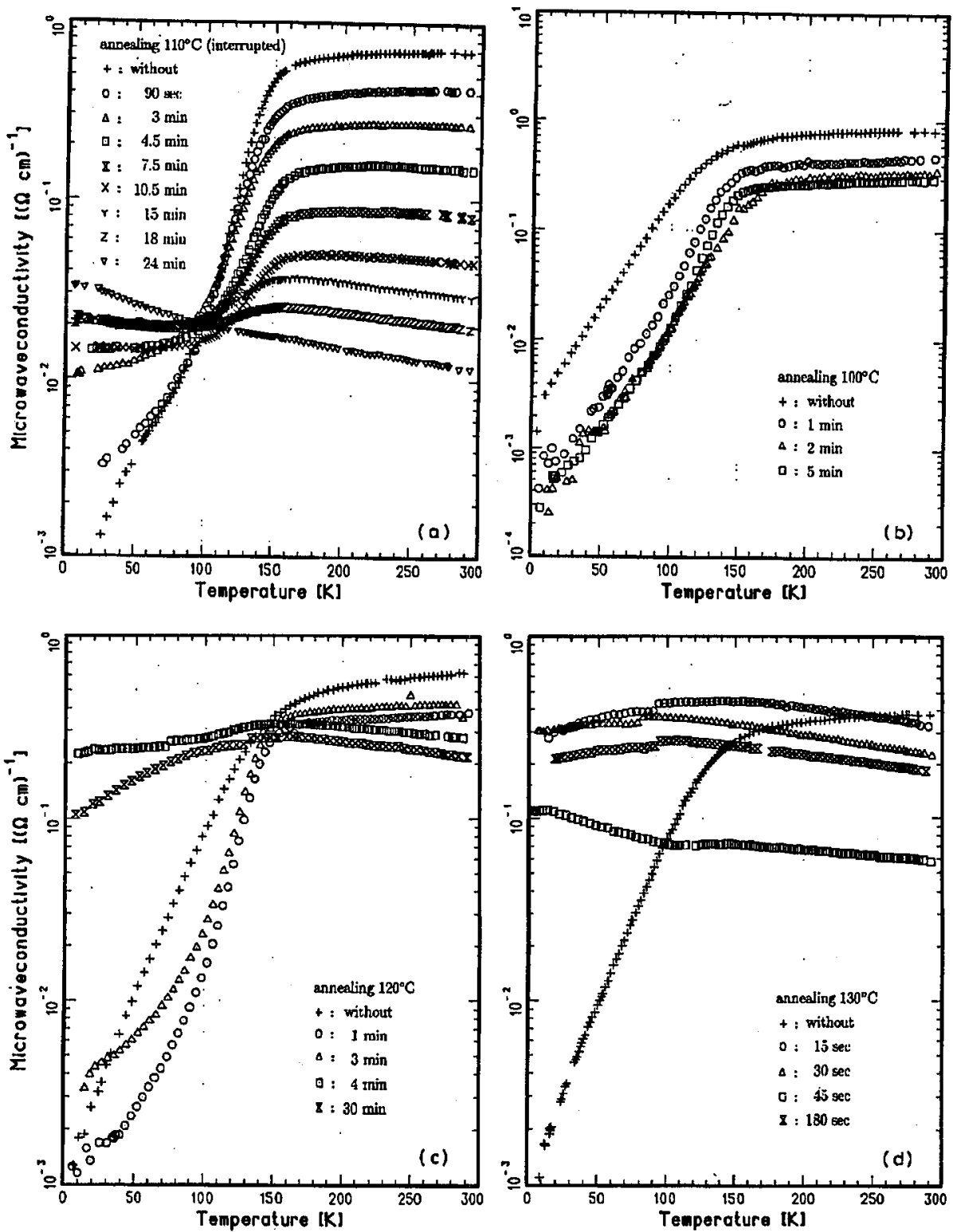

Fig. 1. Temperature dependence of the microwave conductivity $(10.2 \mathrm{GHz})$ of the PC+BEDT-TTF (a) iodide film without annealing and after stepwise annealing of the same sample at $110^{\circ} \mathrm{C},(\mathrm{b})-(\mathrm{d})$ iodide film without annealing and after annealing (without interruption) at $100^{\circ} \mathrm{C}(\mathrm{b}), 120^{\circ} \mathrm{C}(\mathrm{c})$ and $130^{\circ} \mathrm{C}(\mathrm{d})$, annealing times indicated in the figures. 
the annealing time increases steeply and linearly indicating that there is no considerable threshold for the transition (in contrast to the sigmoid character found for pressed polycrystalline samples [10]).

Annealing for $5 \mathrm{~min}$. at $110^{\circ} \mathrm{C}$ without interruption results in a complete transition into the metallic state.

Figures $1 \mathrm{~b}$ to $1 \mathrm{~d}$ show the results of annealing processes without interruption in dependence on different annealing temperatures and times. As one can see in Fig. 1b, an annealing temperature of $100^{\circ} \mathrm{C}$ is too low for a complete phase transformation into the $\alpha_{t}$-phase; there are only very small changes in the conductivity even for a long annealing time of $30 \mathrm{~min}$.

Figure 1c shows the results of an optimal annealing temperature of $120^{\circ} \mathrm{C}$. In the time range 1 to $3 \mathrm{~min}$. intermediate stages could be reached. After only 4 or $5 \mathrm{~min}$. of annealing the transformation into the new $\alpha_{t}$-phase is complete.

At annealing temperatures of $130^{\circ} \mathrm{C}$ (see Fig. 1d) the transformation into $\alpha_{t}$-(ET) ${ }_{2} \mathrm{I}_{3}$ takes place only after $15 \mathrm{~s}$ of annealing. So it is not possible to reach intermediate stages of the transforming process like at $120^{\circ} \mathrm{C}$.

\section{Acknowledgment}

J.U. and J.K.L. acknowledge the support from project 300909101 of the State Committee for Scientific Research (Republic of Poland).

\section{References}

[1] J.K. Jeszka, J. Ulański, M. Kryszewski, Nature 298, 290 (1981); Polish Patent No. 116850 (1979).

[2] L. Burda, A. Tracz, T. Paluka, J. Ulański, M. Kryszewski, J. Phys. D, Appl. Phys. 16, 1737 (1983).

[3] M. Kryszewski, J.K. Jeszka, J. Ulański, A. Tracz, Pure Appl. Chem. 56, No. 3, 355 (1984).

[4] J. Ulański, J.K. Jeszka, A. Tracz, I. Glowacki, M. Kryszewski, E. Laukhina, Synth. Met. 56, 2001 (1993).

[5] H.W. Helberg, D. Staerk, J. Ulański, J.K. Jeszka, Acta Phys. Pol. A 87, (1995).

[6] L.I. Buravov, A.V. Zvarykina, E.E. Laukhina, V.N. Laukhin, R.M. Lobkovskaya, V.A. Merzhanov, N.N. Alejnikov, V. Korokov, R.P. Shibaeva, I.F. Shchegolev, E.B. Yagubskii, Mater Sci. 14, 17 (1988).

[7] G.O. Baram, L.I. Buravov, L.C. Degtariev, M.E. Kozlov, V.N. Laukhin, E.E. Laukhina, V.B. Drischenko, K.L. Pokhodnia, M.K. Scheinkmann, R.P. Shibaeva, E.B. Yagubskii, JETP Lett. 44, 2913 (1986).

[8] D. Schweitzer, P. Bele, H. Brunner, E. Gogu, U. Haeberlen, I. Hennig, T. Klutz, R. Swietlik, H.J. Keller, Z. Phys. B, Condens. Matter 670, 489 (1987).

[9] H.W. Helberg, B. Wartenberg, Z. Angew. Phys. 20, 505 (1966).

[10] G. Müller, H.W. Helberg, D. Schweitzer, H.J. Keller, Synth. Met. 42, 1999 (1991).

[11] K. Bender, K. Dietz, H. Endres, H.W. Helberg, I. Hennig, H.J. Keller, H.W. Schäfer, D. Schweitzer, Mol. Cryst. Liq. Cryst. 107, 45 (1984). 